\title{
Optical repeater for indoor visible light communication using amplify-forward method
}

\author{
Arsyad Ramadhan Darlis, Lucia Jambola, Lita Lidyawati, Adisty Hanny Asri \\ Department of Electrical Engineering, Institut Teknologi Nasional Bandung, Indonesia
}

\begin{abstract}
Article Info
ABSTRACT

Article history:

Received Mar 1, 2020

Revised May 10, 2020

Accepted Jun 5, 2020

\section{Keywords:}

Amplify-forward

Indoor

Long-distance

Optical repeater

Visible light communication

In this paper, the implementation of an optical repeater for indoor visible light communication using the amplify-forward method was proposed. In indoor, visible light communication (VLC) can occur by transmitting information signals from lamps as a VLC transmitter toward the VLC receiver as line-ofsight (LOS) that is located with only a few meters. In the non-los (NLOS) Communication, the signal will be attenuated, so it needs to amplify to improve good signal quality in a VLC receiver. The optical repeater could be used to improve the signal quality that attenuating due to distance. The audio signal was generated and sent using VLC Transmitter toward the light emitting diode (LED). Then, the electrical signal was converted to become visible light, and it was amplified using an optical amplifier with an amplify-forward method. The signal in the form of visible light that had been amplified would be received by the photodiode (PD), and the VLC receiver processed it. The measurement results showed the system that used the optical repeater could improving the distance until $9.5 \mathrm{~m}$ with frequency $6000 \mathrm{~Hz}$, where the best signal quality at a frequency of $3000 \mathrm{~Hz}$. The measurement result showed that the use of repeater components with the amplify-forward method for VLC systems, especially in the room, can increase the range until $4.5 \mathrm{~m}$ compare without an optical repeater. This result exceeds the minimum distance of an indoor visible light communication system, with an average distance of the roof to the floor is $3.5 \mathrm{~m}$.
\end{abstract}

Copyright $(0) 2020$ Institute of Advanced Engineering and Science. All rights reserved.

\section{Corresponding Author:}

Arsyad Ramadhan Darlis,

Department of Electrical Engineering, Institut Teknologi Nasional Bandung,

PKH. Mustapha Street No. 24 Bandung 40124, West Java, Indonesia.

Email: arsyad@itenas.ac.id

\section{INTRODUCTION}

Communication systems that occur from year by year are growing. In communication technology, various ways of delivering information can be done, both wired and wireless, as well as visible light, which only has one function, like lighting. The room lighting at this time has a lot that uses Light Emitting Diode (LED) as its main component. Theoretically, the light from LED can be used for high-speed communication. Visible Light Communication (VLC) is a communication system that uses visible light as a transmission that possible to transmit data or use it as a sender for sound, audio, and video. However, the problem that arises in visible light communication itself is the weakening of the signal as distance increases. If the range is getting farther away, the beam of light will weaken. It will be a problem to build good communication, so to overcome this, a repeater is needed to increase the range.

In 2015, research was conducted by [1] and his team regarding the design and implementation of Visible Light Communication devices as radio transceivers. A VLC device was developed to transmit analog video signals. The video signal is sent via an LED on the transmitter block. Then it is received by the receiver block, with the photodiode as the recipient of the information. In the process of sending, the video signal is 
divided into two parts, i.e., sound and video signals. In 2018, there was research conducted by [2], on the topic of implementing Visible Light Communication (VLC) in communication systems using Raspberry Pi.

The research conducted by Omer Narmanlioglu [3] examined the performance of visible light communication systems (VLC), which assisted relays with multipath channels by simulating and using the indoor. The light on the ceiling lights serves as a source of information, and the desk lamp helps source information to the destination. In 2014, the research conducted by Jingyuan Duan [4] with simulation methods related to the commercialization of visible light communication technology (VLC) faced several obstacles such as high complexity, poor mobility, heterogeneous integration with TCP/IP networks, multiaccess, large size and others.

In 2015 the research was conducted by Caglar Kizilirmak Refik [5], a visible light communication system (VLC) was assisted by a relay where the intermediate light source cooperated with the main light source. In particular, this research considers two light sources in office space. The first is a source of information placed on the ceiling, and the other is a system using multiplexing DC orthogonal optical multiplexing (DCO-OFDM), where light tasks carry out relaying to aid communication and operate in half-duplex mode for both amplifyand-forward and decode-and-forward relaying. As for 2013, in [6] conducted a full-duplex VLC relay study on LED lighting with linear system topology with simulation methods.

The other research on VLC has covered various aspects in certain applications, i.e. in rooms [7-15], vehicles [16, 17], computer networks [18, 19], cameras [20, 21], and underwater [22-26]. Currently, VLC research has utilized artificial intelligence in its application [27, 28]. Due to the enhancement of the application of VLC, then it also needs performance improvement, especially in terms of distance.

In indoor, Visible Light Communication (VLC) can occur by transmitting information signals from Lamps as a VLC transmitter toward the VLC receiver as Line-of-Sight (LOS) that is located with only a few meters. In the Non-LOS (NLOS) Communication, the signal will be attenuated, so it needs to amplify to improve good signal quality in a VLC receiver. The optical repeater could be used to improve the signal quality that attenuating due to distance. In this research, implementation Optical Repeater for Indoor Visible Light Communication using the Amplify-Forward method, which is expected to increase the range of the system.

\section{RESEARCH METHOD}

The system designed is divided into three parts, i.e., the Transmitter (Tx), Receiver (Rx), and Repeater. The Tx and Rx circuits will be designed in advance to obtain the desired system performance. Then the repeater circuit is designed to get the expected results. After the design is complete, it will be combined into a system to get one link, the transmitter, repeater, and receiver. The transmitter is connected to the LED while the receiver is connected to the photodiode. Figure 1 shows the diagram block of communication method design.

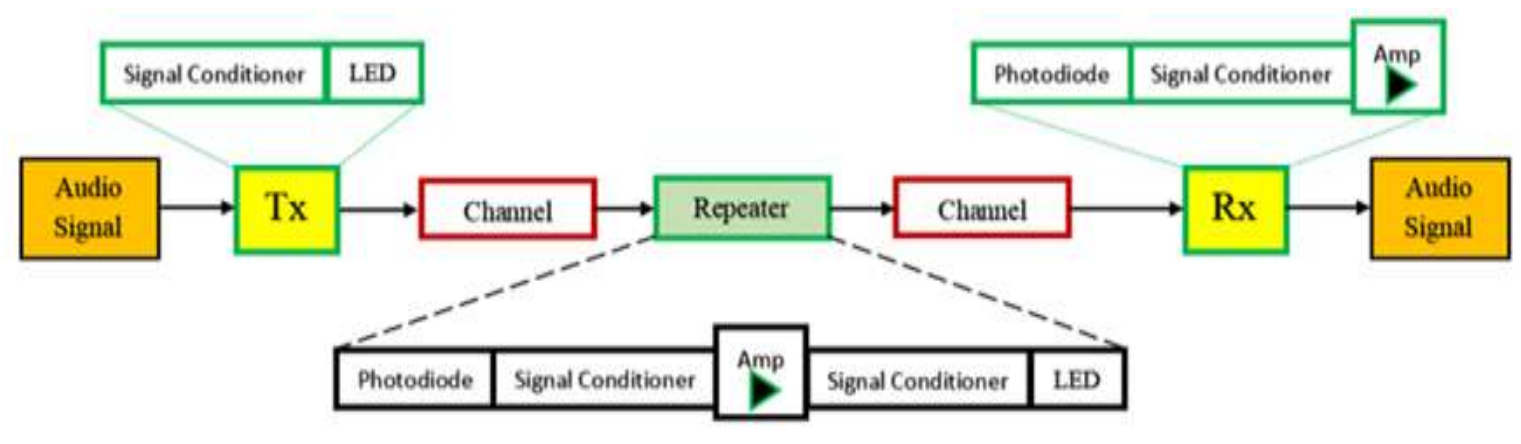

Figure 1. Diagram block of communication method design

The transmitter explains that the input containing the information signal in the form of frequencies from 340 to $3400 \mathrm{~Hz}$ is generated with an audio generator device and then processed at the transmitter circuit to be transmitted through visible light using an LED. The light will be transformed by a device that serves to convert light signals to electrical signals is a photodiode. The signal will be conditioned again and amplified. Signal conditioning will be carried out by the signal conditioner. The output of the amplifier block will undergo a transformation process from the electrical signal to light using LED components so that it can be transmitted back through the air medium. With prior signal conditioning, an electrical signal is processed in the receiver circuit and will be converted into a voice signal again. 


\subsection{VLC Transmitter}

At the transmitter (Tx), there is a process of converting information signals that are processed by signal conditioners into a form of light then transmitted through the LED. When sending information in the form of visible light waves, the LED will emit visible light, according to the input signal given. Figure 2 shows the VLC transmitter circuit.

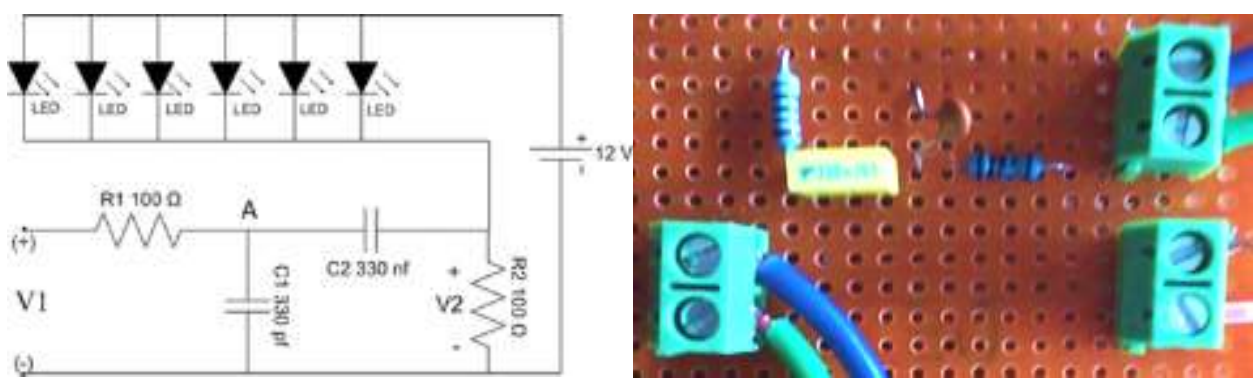

Figure 2. VLC transmitter circuit

Input is a signal generator that is connected to the cable to the VLC transmitter circuit. The audio generator will act as an input signal with a frequency of $3 \mathrm{kHz}$. This VLC transmitter circuit functions to send information signals emitted by LED in the form of visible light. The voltage is given to send an information signal of $12 \mathrm{~V}$, to eliminate unwanted signals, the input signal from the audio generator will be filtered using a Band Pass Filter (BPF) before being transmitted through light with an LED. The input signal transmitted by the transmitter can be seen using an oscilloscope.

\subsection{VLC Receiver}

In the VLC receiver, there is a process of receiving information signals that have been sent from the VLC transmitter in the form of visible light, which will then be received by the photodiode circuit and converted into an information signal again. The following is a series of receivers used in research. Figure 3 shows the VLC receiver circuit.
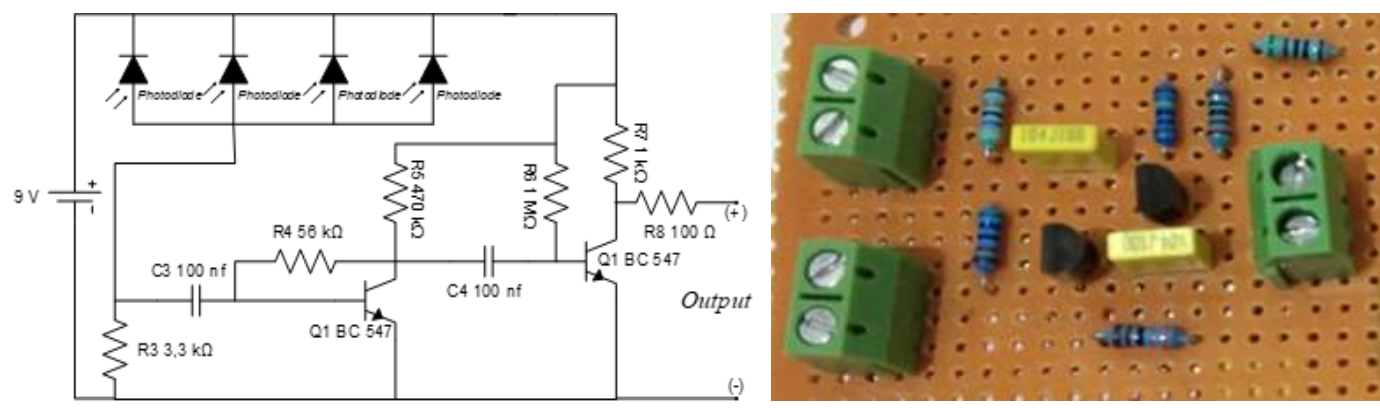

Figure 3. VLC receiver circuit

\subsection{VLC Repeater}

The VLC repeater circuit serves to increase the range of the transmit signal. In this repeater circuit, the signal sent, will be amplified and then transmitted back to the receiving component so that the output signal is optimal. Figure 4 shows the VLC optical repeater circuit.

The method used in this system is the Amplify-Forward (AF), which is when each node co-operatively receives a version of the noise signal from the signal reception. Then, this node will amplify and resend the signal of the noise version. In other words, the relay terminal will send the information signal it receives into the second channel at the sending terminal after providing reinforcement and then forward it back to the desired receiving terminal. 


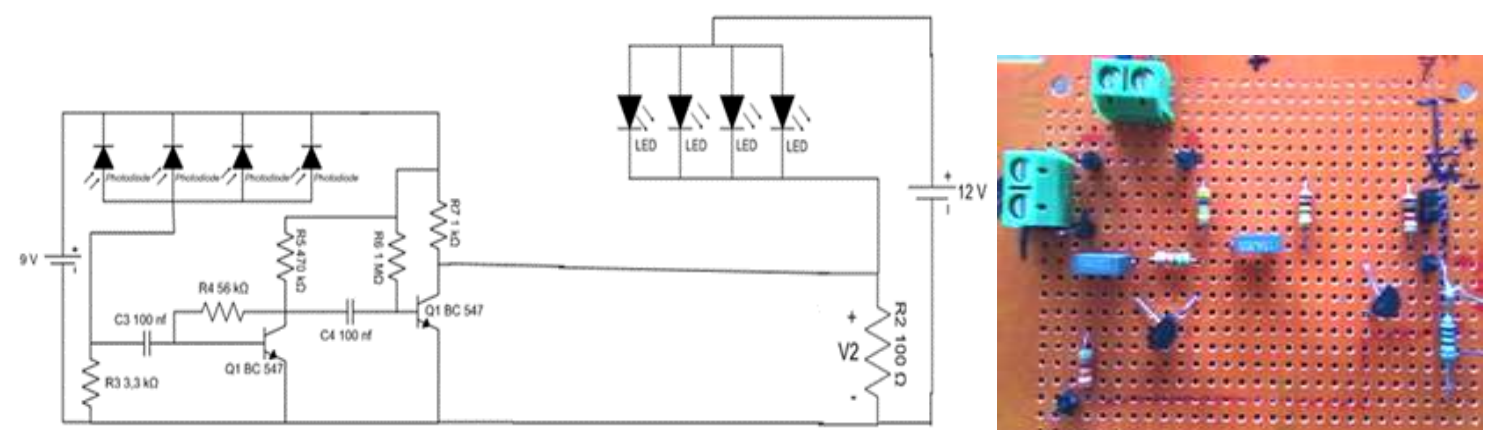

Figure 4. VLC optical repeater circuit

\section{RESULTS AND DSCUSSION}

This measurement aims to determine the performance of the VLC transmitter system, VLC repeater, and VLC receiver that had previously been designed. The measures taken in this research are as follows.

1. Measurement-based on changes in distance without the repeater

2. Measurement-based on changes in distance using the repeater

3. Measurement-based on frequency VLC systems without and using a repeater.

\subsection{Measurement-based on changes in distance without the repeater}

This measurement aims to determine the reliability of the system in sending and receiving audio signals to reach the maximum range. Signals with a set frequency of $3 \mathrm{kHz}$ are generated with an audio generator and a reference voltage of $5 \mathrm{Vpp}$. The measurement block diagram of the VLC system is shown in Figure 5.

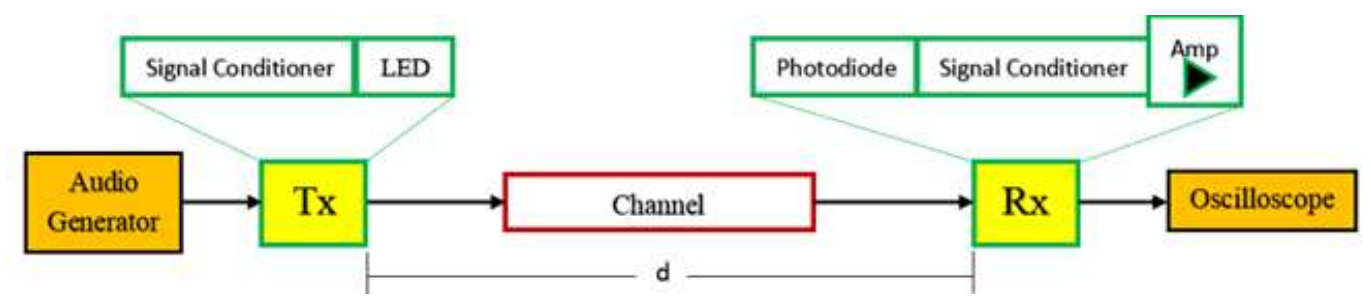

Figure 5. Measurement block diagram based on changes in distance without the repeater

From the measurement results based on the distance between VLC transmitters and VLC receivers without using a repeater device, the measurement results data obtained in Figure 6.

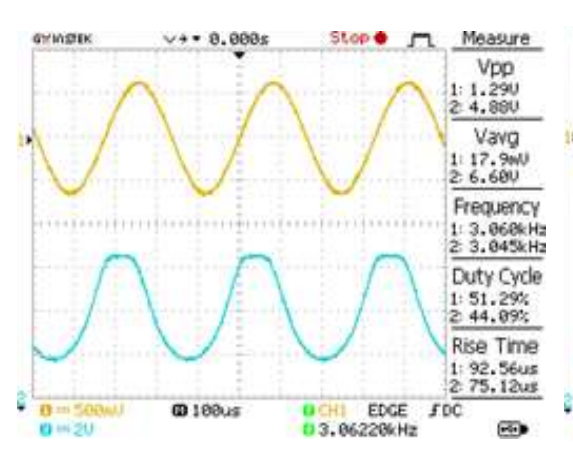

(a)

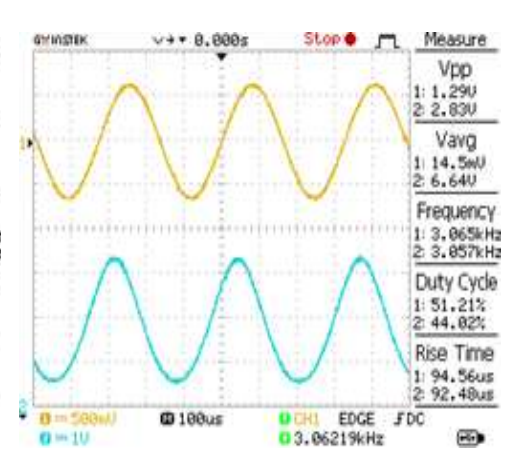

(b)

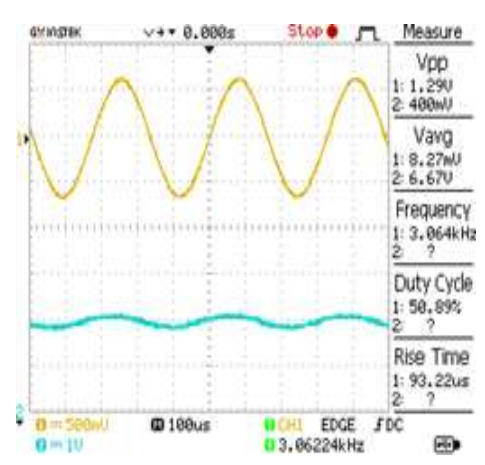

(c)

Figure 6. Output signal based on changes in distance without the repeater, (a) $1 \mathrm{~m}$, (b) $2 \mathrm{~m}$, (c) $7 \mathrm{~m}$ 
Based on the measurement data obtained $\mathrm{V}$ output, which is generated from changes in the distance between VLC transmitter and VLC receiver without using a repeater device, indicated by a chart of voltage and the distance in Figure 7. From the measurement results based on distance changes, the graph shows that the output voltage of the receiver has decreased signal quality as distance increases. In Figure 7, can be reviewed, at a distance of $1 \mathrm{~m}$ obtained an output voltage of $4.88 \mathrm{Vpp}$, a distance of $1.5 \mathrm{~m}$ output voltage of $3.68 \mathrm{Vpp}$, then at a distance of $2 \mathrm{~m}$ obtained an output voltage of $2.83 \mathrm{Vpp}$ and an output voltage of $400 \mathrm{mVpp}$ obtained at a maximum distance of $7 \mathrm{~m}$. The farther the distance traveled between the transmitter and receiver, the lower the output voltage is lower, meaning that the signal performance is decreasing. This can occur because the farther the distance between the sender and the receiver, the greater the beam of the signal that occurs so that the radiating light will be narrower the scope of the catch on the receiver. So that from the measurement data, the maximum distance obtained on the VLC system without using a repeater device is reaching $7 \mathrm{~m}$.

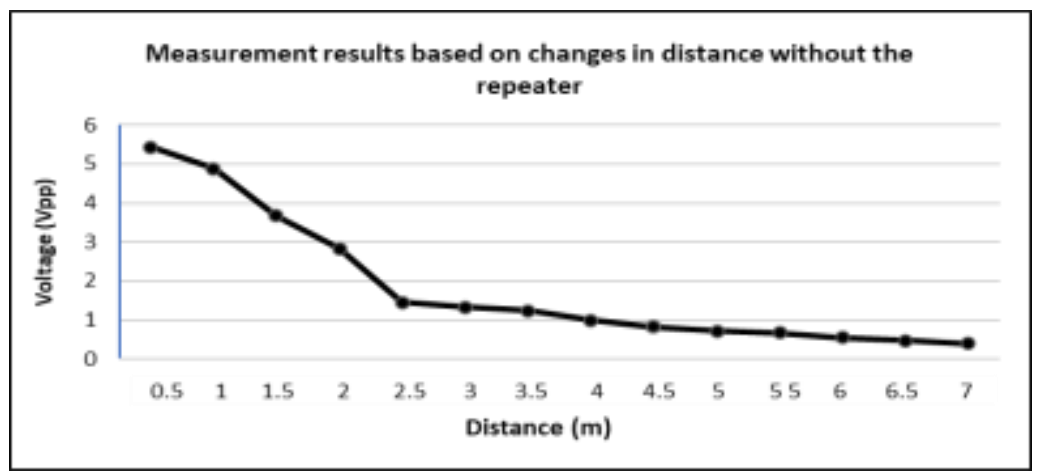

Figure 7. Measurement results based on changes in distance without the repeater

\subsection{Measurement-based on changes in distance using the repeater}

This measurement aims to determine the system reliability obtained after the repeater component is inserted. The VLC repeater component is expected to increase the range of the system that occurs. The distance between the transmitter and the repeater is not changed; it remains at a distance of $d_{1}$, which is $0.5 \mathrm{~m}$. The receiver component will be moved away from the repeater based on the distance $\mathrm{d}_{2}$. The set frequency is $3 \mathrm{kHz}$ generated by an audio generator with a reference voltage of $5 \mathrm{Vpp}$. The measurement method of the VLC system is shown in Figure 8.

From the measurement results based on changes in distance between VLC transmitters and VLC receivers using a repeater device, the measurement results data obtained are shown in Figure 9. From the measurement results based on the distance changes shown in Figure 9, the value of the output voltage at a distance of $1 \mathrm{~m}$ is $5.92 \mathrm{Vpp}$, then for the output voltage at a distance of $1.5 \mathrm{~m}$ is $5.59 \mathrm{Vpp}$. At a distance of $2 \mathrm{~m}, \mathrm{~V}$ output obtained at $5.51 \mathrm{Vpp}$. Moreover, at a distance of $9.5 \mathrm{~m}$ or the maximum distance of the system, the output voltage is $444 \mathrm{mVpp}$. Based on the measurement data obtained output voltage (V output), which is generated from changes in the distance between VLC transmitter and VLC receiver without using a repeater, indicated by a graph of the voltage against distance in Figure 10.

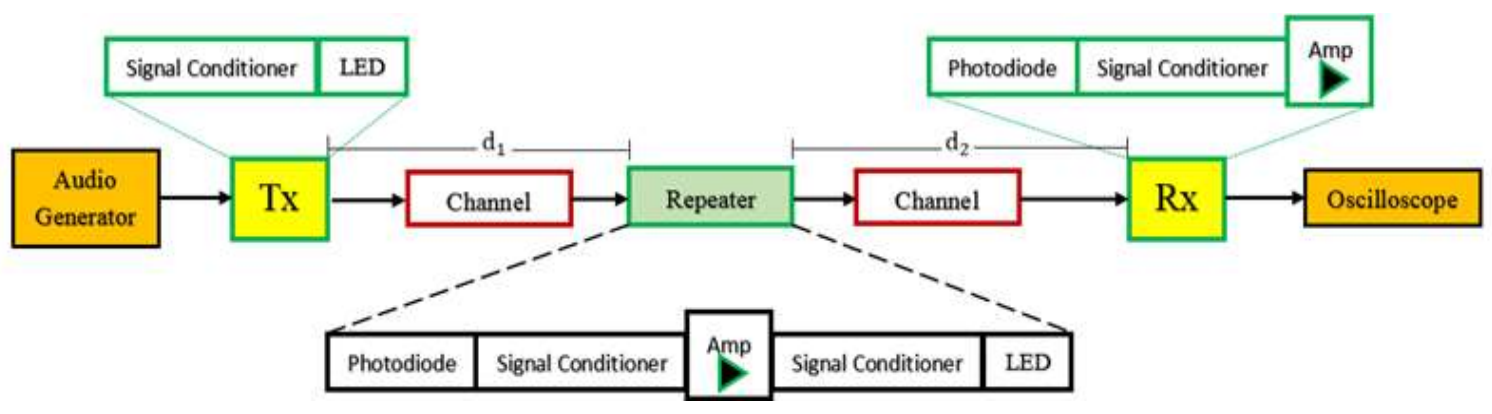

Figure 8. Measurement block diagram based on changes in distance using the repeater 


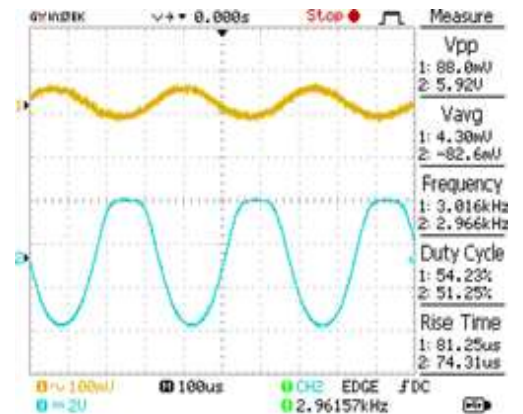

(a)

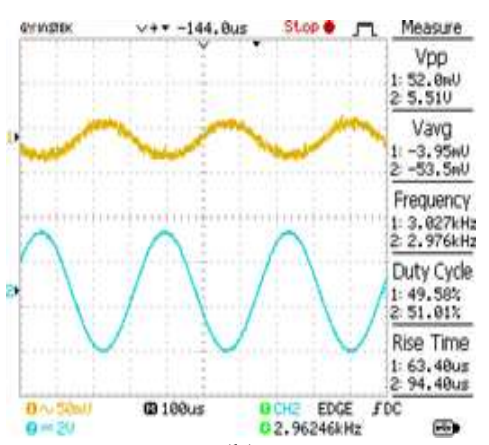

(b)

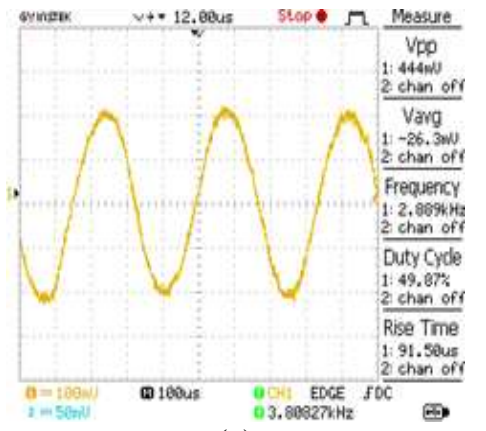

(c)

Figure 9. Output signal based on changes in distance using the repeater, (a) $1 \mathrm{~m}$, (b) $2 \mathrm{~m}$, (c) $9.5 \mathrm{~m}$

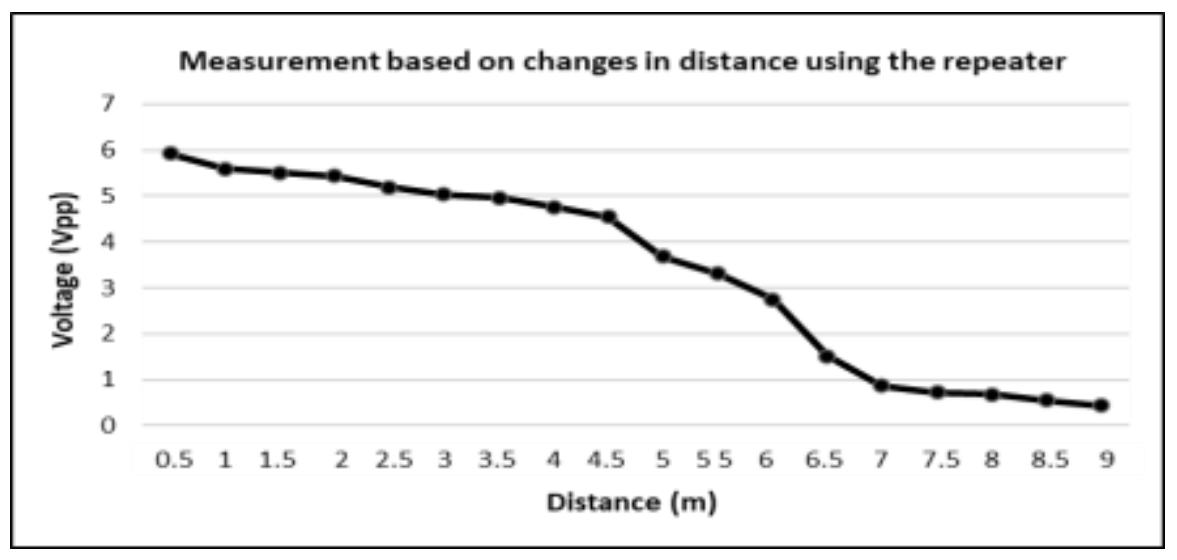

Figure 10. Measurement results based on changes in distance without the repeater

From the measurement results, after the repeater component is inserted, the test is based on changes in the distance between the repeater and the receiver, on the graph shows the output voltage of the receiver has decreased signal quality as distance increases. This can occur due to the use of repeater components in this system, making the distance traveled due to the strengthening of the signal before the signal is transmitted to the receiver component. The following is a graph of the comparison of measurements based on distance changes before being inserted and after the repeater device has been inserted. Figure 11 show comparison measurements based on distance without and using repeater

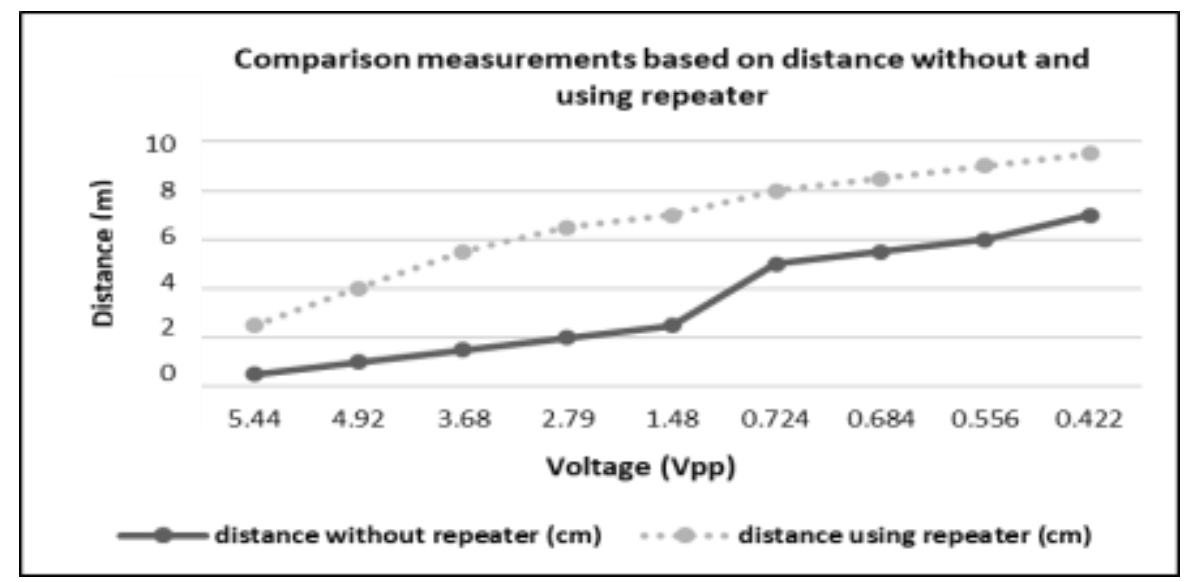

Figure 11. Comparison measurements based on distance without and using repeater 
From the measurement results and the comparison with the graph, it shows that the output voltage on the receiver is more increased when using a repeater device. At a reference voltage of 5.44 Vpp, the distance traveled without using a repeater is $0.5 \mathrm{~m}$ while using a repeater is $2.5 \mathrm{~m}$. At a reference voltage of $422 \mathrm{mVpp}$, the distance traveled without using a repeater is $7 \mathrm{~m}$ while using a repeater is $9.5 \mathrm{~m}$. This can happen because, in the repeater device, there is a return signal amplification; that is, the signal conditioned by the signal conditioner is amplified by using a transistor component, before being sent to the receiver. While the response of the system without using a repeater only experienced a one-time gain, that is, on the receiver component only. By using a repeater on the VLC system, it can increase the range or increase the distance between the range $2 \mathrm{~m}$ until $4.5 \mathrm{~m}$. This is caused by conditions that are not ideal reinforcement and interference that occurs in the signal.

Furthermore, reinforcement measurements carried out directly on the repeater component show a comparison between the output voltage and the input voltage. Analog signal input comes from an audio generator with a reference voltage of $5 \mathrm{Vpp}$ and a given frequency of $3000 \mathrm{~Hz}$. This reinforcement measurement is done repeatedly at intervals of 10 minutes for five times.

Figure 12 shows Signal Strength Measurement Results on the Repeater. It shows the first signal shows a voltage of $3.20 \mathrm{Vpp}$, which is the input voltage of the repeater, and a voltage of $4.15 \mathrm{Vpp}$ indicates the repeater output voltage. Obtaining data that appears on the graph, Then from the results of repeated measurements for five times the average value of $\mathrm{V}$ input is $2.548 \mathrm{Vpp}$, and the average $\mathrm{V}$ output is $4.166 \mathrm{Vpp}$, so that the magnitude of the repeater device can be known become $1.63 \mathrm{x}$.
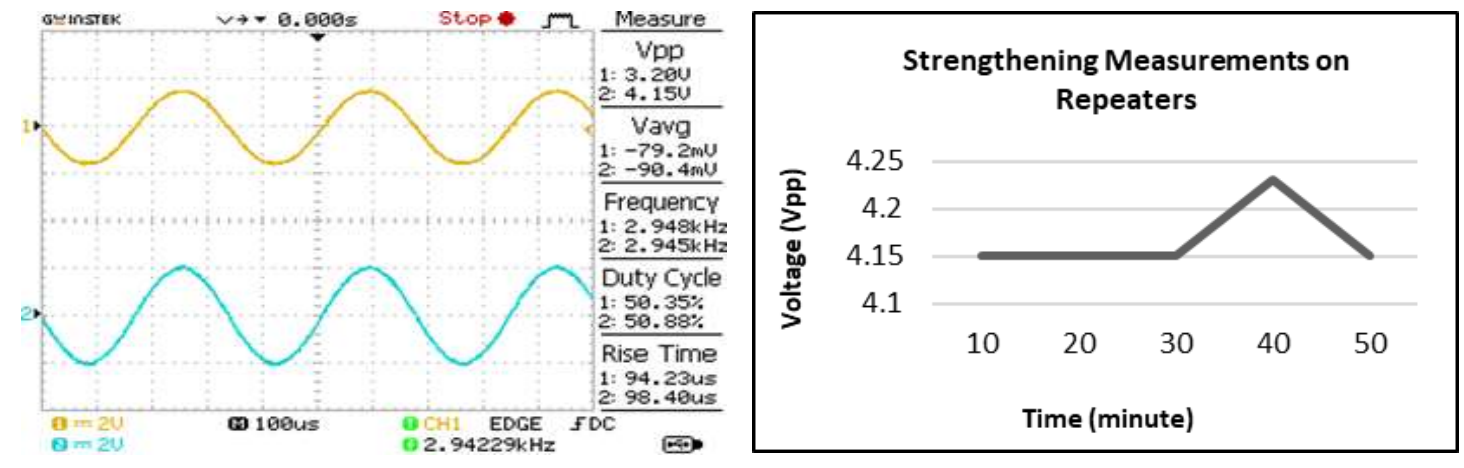

Figure 12. Signal strength measurement results on the repeater

\subsection{Measurement-Based on Frequency in VLC Systems without and Repeater}

This measurement aims to determine the condition of the system still in the audio frequency interval of $340 \mathrm{~Hz}-3400 \mathrm{~Hz}$. The VLC system sends and receives audio signals with a range that is set to $1 \mathrm{~m}$. The signal with the tested frequency range is between $100 \mathrm{~Hz}-100 \mathrm{k} \mathrm{Hz}$ generated by the audio generator with a reference voltage of $5 \mathrm{Vpp}$. Figure 13 show the method of measurement based on frequency in VLC systems without a repeater and fhis measurement method using repeater is shown in Figure 14.

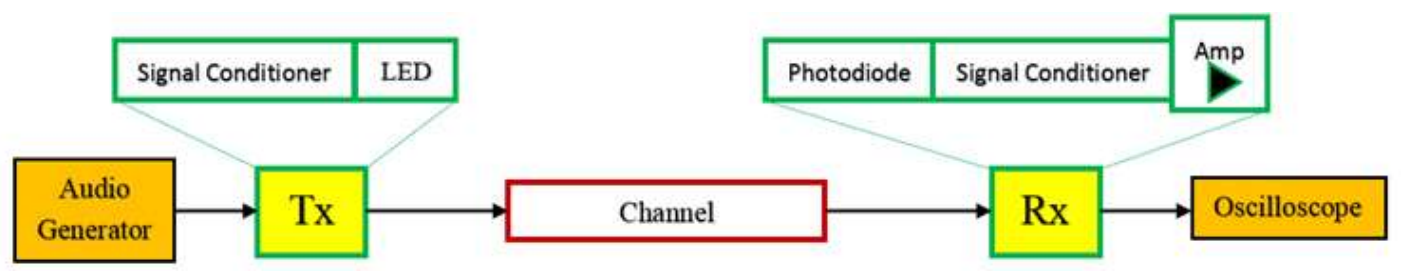

Figure 13. Method of measurement based on frequency in VLC systems without repeater

Figure 14 shows the measurement aims to determine the reliability of the system in sending and receiving signals with a distance of $0.5 \mathrm{~m}$ between the transmitter and the repeater and a distance of $0.5 \mathrm{~m}$ between the repeater and the receiver. Also, to indicate the working frequency limit of the signal on the system. A signal with a transmitted frequency range between $100 \mathrm{~Hz}-60 \mathrm{kHz}$ is generated with an audio generator and a reference voltage of $5 \mathrm{Vpp}$. The following is a measurement method diagram based on setting

Optical repeater for indoor visible light communication using amplify-forward... (Arsyad Ramadhan Darlis) 
several frequencies on the VLC system using a repeater device. From the results of the two measurements and obtained the data, the results of the comparison of frequency based measurements without and using repeater is shown in Figure 15.

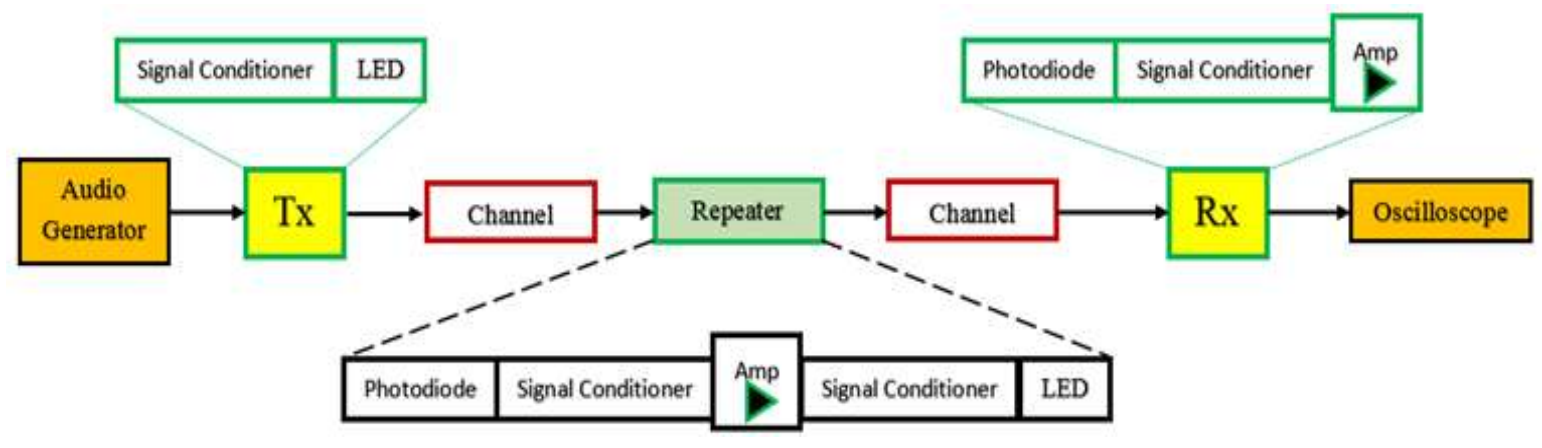

Figure 14. Method of measurement based on frequency in VLC systems using a repeater

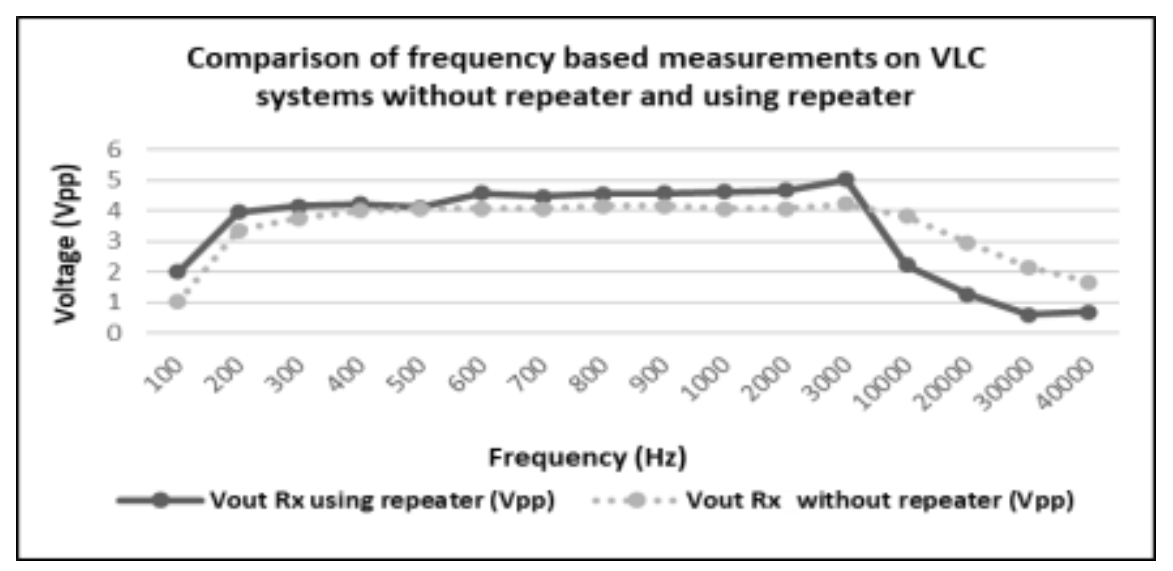

Figure 15. Comparison of frequency-based measurements on VLC systems without and using a repeater

From the measurement results without repeater based on frequency changes at a distance of $1 \mathrm{~m}$ between the transmitter and receiver in Figure 15, it shows that the higher the frequency is given, the lower the output voltage. Also, at a frequency of $300 \mathrm{~Hz}-10000 \mathrm{~Hz}$ shows an output voltage that is more than or equal to $4.00 \mathrm{Vpp}$ if averaged, there is a value of $4,025 \mathrm{Vpp}$. Then the signal quality decreases at a frequency of 20000 $\mathrm{Hz}-100000 \mathrm{~Hz}$. Meanwhile, the measurement results without repeater at a distance of $1 \mathrm{~m}$ between the transmitter and receiver $(0.5 \mathrm{~m}$ between the transmitter and repeater and $0.5 \mathrm{~m}$ between repeaters and receivers), the graph shows the output voltage ( $\mathrm{V}$ output) more than or equal to $4.00 \mathrm{Vpp}$ at intervals of $200-7000 \mathrm{~Hz}$ results in an average voltage of $4.19 \mathrm{Vpp}$. Then the signal quality decreases at a frequency of $10000 \mathrm{~Hz}-60000 \mathrm{~Hz}$; the higher the frequency, the higher the voltage.

From the measurement results and comparisons with the graph, it shows that the overall output voltage at the frequency interval $100-60000 \mathrm{~Hz}$ before the repeater device is inserted in the VLC system is $3.78 \mathrm{Vpp}$, and after the repeater is inserted the output voltage decreases to $3.14 \mathrm{Vpp}$. This can occur because the use of repeater components on the VLC system that has been designed, creates a loading effect that affects the amount of output voltage (V output) produced. From the graph, the working frequency limit of the system using a repeater is less than or equal to $6000 \mathrm{~Hz}$. This can be indicated by the effect of strengthening the signal. At frequencies above $6000 \mathrm{~Hz}$, the repeater's influence is not visible, and there is no reinforcement. The working frequency of this system has met the audio frequency limit, which is $340-3400 \mathrm{~Hz}$. Also, from the graph, it can be seen that the best frequency range is found at a frequency of 3000-4000 Hz can be seen from the highest voltage produced by the system. 


\section{CONCLUSION}

In this research, the VLC system device designed and implemented can send signals with audio frequencies of 300-3000 Hz. The measurement results of the maximum distance without a repeater obtained a length of $7 \mathrm{~m}$, while after using the repeater, the range was $9.5 \mathrm{~m}$. Then, the measurement results of the working frequency on the system have a maximum limit of $6000 \mathrm{~Hz}$ so that the system has fulfilled the audio working frequency, which is in the range $340-3400 \mathrm{~Hz}$, by using an optical repeater device on the communication system. The visible light can increase the range between $2.5 \mathrm{~m}$ until $4.5 \mathrm{~m}$ with an average gain of 1.63 times. The overall comparison test results show that the use of optical repeater components with the amplify forward method for VLC systems, especially in the room, can increase the range to $4.5 \mathrm{~m}$ to communicate with good signal quality at a frequency of $3000-4000 \mathrm{~Hz}$, and this result exceeds the minimum distance of an indoor visible light communication system, with an average distance of the roof to the floor is $3.5 \mathrm{~m}$ for LOS Communication.

\section{ACKNOWLEDGEMENTS}

This research was supported by Hibah Penelitian Terapan Unggulan Perguruan Tinggi (PTUPT) 2020 funded by the Kementerian Riset, Teknologi, dan Pendidikan Tinggi Republik Indonesia.

\section{REFERENCES}

[1] M. Mehrabi, et al., "Frame Synchronization of Live Video Streams Using Visible Light Communication," IEEE International Symposium on Multimedia (ISM), 2015.

[2] T. Wang and Z. Zhao, "An implementation of visible light communication based on Raspberry Pi," IEEE Integrated STEM Education Conference (ISEC), 2018.

[3] O. Narmanlioglu, et al., "Relay Assisted OFDM-Based Visible Light Communications over Multipath Channels," 17th International Conference on Transparent Optical Networks (ICTON), 2015.

[4] J. Duan, et al., "A Practical Indoor Visible Light Communication System," 9th International Symposium on Communication Systems, Networks \& Digital Sign (CSNDSP), 2014.

[5] C. R. Kizilirmak, et al., "Relay Assisted OFDM-Based Visible Light Communications," IEEE Transactions on Communications, vol. 63, no. 10, pp. 3765-3778, 2015.

[6] H. Yang and A. Pandharipande, "Full-duplex Relay VLC in LED Lighting Linear System Topology," 39th Annual Conference of the IEEE Industrial Electronics Society, 2013.

[7] Q. Zhao, et al., "A low complexity power allocation scheme for NOMA-based indoor VLC systems," Optics Communications, vol. 463, p. 125383, 2020.

[8] X. Peng and L. Kong, "Design and optimization of optical receiving antenna based on compound parabolic concentrator for indoor visible light communication," Optics Communications, vol. 464, p. 125447, 2020.

[9] F. A. Dahri, et al., "Design and implementation of LED-LED indoor visible light communication system," Physical Communication, vol. 38, p. 100981, 2020.

[10] R. C. Kizilirmak, "Impact of repeaters on the performance of indoor visible light communications," Turkish Journal of Electrical Engineering and Computer Sciences, vol. 23, no. 4, pp. 1159-1172, 2015.

[11] K. Bandara, et al., "Improved indoor visible light communication with PAM and RLS decision feedback equalizer," IETE Journal of Research, vol. 59, no. 6, pp. 672-678, 2013.

[12] M. S. Rahman and K. D. Kim, "Indoor location estimation using visible light communication and image sensors," International Journal of Smart Home, vol. 7, no. 1, pp. 99-114, 2013.

[13] Y. Yi, et al., "Optimum spread code applied in indoor visible light data transmission for optical multipath dispersion reduction," IETE Technical Review (Institution of Electronics and Telecommunication Engineers, India), vol. 30, no. 3, pp. 233-239, 2013.

[14] T. Zhang, et al., "Enhancing the bit error rate of indoor visible light communication systems using adaptive channel estimation algorithm," IET Communications, vol. 9, no. 4, pp. 501-507, 2015.

[15] M. S. Rahman and K. Kim, "Indoor Positioning By Led Visible Light Communication And Image Sensors," Int. J. Electr. Comput. Eng, vol. 1, no. 2, pp. 161-170, 2011.

[16] X. You, et al., "Mobile channel estimation based on decision feedback in vehicle-to-infrastructure visible light communication systems," Optics Communications, vol. 462, p. 125261, 2020.

[17] N. Kim, et al., "Smart parking information system exploiting visible light communication," International Journal of Smart Home, vol. 8, no. 1, pp. 251-260, 2014.

[18] A. Burton, et al., "Experimental demonstration of a 10BASE-T Ethernet visible light communications system using white phosphor light-emitting diodes," IET Circuits, Devices and Systems, vol. 8, no. 4, pp. 322-330, 2014.

[19] N. T. Le and Y. M. Jang, "Virtual cognitive MAC for visible light communication system," International Journal of Smart Home, vol. 6, no. 2, pp. 95-100, 2012.

[20] N. Rajagopal, et al., "Hybrid visible light communication for cameras and low-power embedded devices," VLCS 2014 - Proceedings of the 1st ACM MobiCom Workshop on Visible Light Communication Systems, pp. 33-38, 2014.

[21] R. LiKamWa, et al., "Styrofoam: A tightly packed coding scheme for camera-based visible light communication," VLCS 2014 - Proceedings of the 1st ACM MobiCom Workshop on Visible Light Communication Systems, pp. 27-32, 2014.

Optical repeater for indoor visible light communication using amplify-forward... (Arsyad Ramadhan Darlis) 
[22] A. R. Darlis, et al., "Shore-To-Undersea Visible Light Communication," Wireless Personal Communication, vol. 99, no. 2, pp. 681-694, 2018.

[23] C. Periasamy, et al., "Led Lamp Based Visible Light Communication In Underwater Vehicles," Int. J. Eng. Trends Technol., vol. 13, no. 3, pp. 103-106, 2014.

[24] T. Fickenscher, et al., "Underwater Wireless Optical Communication For Swimmer Feedback Using Irda Transceiver," Electron. Lett., vol. 47, no. 24, pp. 1335-1336, 2011.

[25] B. Tian, et al., "Design and development of an LED-based optical communication system for autonomous underwater robots," IEEE/ASME International Conference on Advanced Intelligent Mechatronics: Mechatronics for Human Wellbeing, pp. 1558-1563, 2013.

[26] A. R. Darlis, et al., "Bidirectional Underwater Visible Light Communication," International Journal of Electrical And Computer Engineering (IJECE), vol. 8, no. 6, pp. 5203-5214, 2018.

[27] M. Sönmez, "Artificial neural network-based threshold detection for OOK-VLC Systems," Optics Communications, vol. 460, p. 125107, 2020.

[28] X. Wu, et al., "Deep neural network method for channel estimation in visible light communication," Optics Communications, vol. 462, 2020.

\section{BIOGRAPHIES OF AUTHORS}
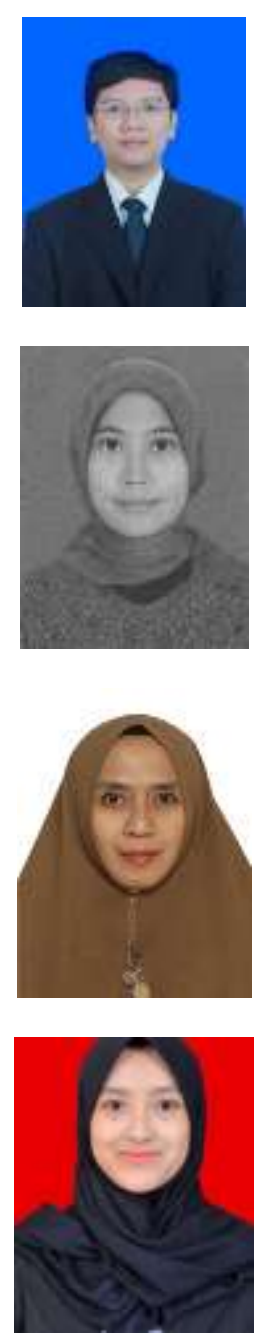

Arsyad Ramadhan Darlis received a B.Sc. on Electrical Engineering from Institut Teknologi Nasional Bandung, Indonesia, in 2009 and an M.Sc. on Telecommunication Engineering from Institut Teknologi Bandung (ITB), Indonesia, in 2011, respectively. His research interests are underwater visible light communications, digital signal processing, and Internet-of-Things. He is currently a lecturer in Institut Teknologi Nasional Bandung.

Lita Lidyawati was born in Yogyakarta (Indonesia), on March 9, 1977. She graduated The Institut Teknologi Nasional Bandung, Department of Electrical Engineering, Indonesia, in 2000. He received a Master's degree in electrical engineering from the Institut Teknologi Bandung (ITB), Indonesia, in 2005. His research interests are visible light communications and signal processing. He is currently a lecturer in Institut Teknologi Nasional Bandung.

Lucia Jambola was born in Bandung (Indonesia), on July 3, 1977. She graduated The Institut Teknologi Nasional Bandung, Department of Electrical Engineering, Indonesia, in 2001. He received a Master's degree in electrical engineering from the Institut Teknologi Bandung (ITB), Indonesia, in 2006. His research interests are optical communication and wireless communications. He is currently a lecturer in Institut Teknologi Nasional Bandung.

Adisty Hanny Asri was born in Yogyakarta (Indonesia), on November 19, 1996. She graduated The Institut Teknologi Nasional Bandung, Department of Electrical Engineering, Indonesia. His research interests are optical communication. 